\title{
Meta-Analisis Penerapan Blended Learning dan Pemilihan Media Online yang Digunakan Terhadap Hasil Belajar
}

\author{
Mega Putriana $^{1^{*}}$, Gde Agus Yudha Prawira Adistana ${ }^{2}$ \\ ${ }^{1,2}$ Pendidikan Teknik Bangunan, Universitas Negeri Surabaya
}

*Corresponding Author. E-mail: mega.17050534012@mhs.unesa.ac.id

Receive: $13 / 05 / 2021$

Accepted: 23/08/2021

Published: 01/10/2021

\begin{abstract}
Abstrak
Perkembangan teknologi memberikan banyak manfaat dalam dunia pendidikan, salah satunya yaitu pendidikan yang dapat dilaksanakan secara online. Pembelajaran online yang dimaksud adalah blended learning, dengan diadakannya model blended learning diharapkan dapat memberikan solusi atas permasalahan dalam kegiatan pembelajaran terutama pada hasil belajar siswa. Dalam penelitian ini dilakukan meta-analisis terhadap 15 artikel dari jurnal nasional mengenai penerapan model pembelajaran blended learning terhadap hasil belajar, metode meta-analisis digunakan untuk mencari nilai effect size yang dapat mengkategorikan keberhasilan blended learning. Proses pembelajarannya didukung dengan penggunaan media atau platform yang menjadi fasilitas perantara antara guru dengan siswa, jenis platform yang digunakan dalam 15 artikel tersebut adalah Google Classroom dengan nilai $\overline{E S}=0,94$, Edmodo dengan dengan nilai $\overline{E S}=0,81$, Whatsapp dengan nilai $\overline{E S}=2,41$, Web Enhanced Course dengan nilai $\overline{E S}=1,34$, Quipper School dengan nilai $\overline{E S}=0,76$ ,dan $L M S$ dengan nilai $\overline{E S}=2,30$. Hasil kategori effect size tersebut masuk kedalam efek sedang hingga tinggi, yang artinya dari meta-analisis terhadap 15 artikel dari jurnal ilmiah menunjukkan bahwa penerapan blended learning terbukti mampu meningkatkan hasil belajar pada siswa.
\end{abstract}

Kata Kunci: Blended Learning, Hasil Belajar, Meta-analisis.

\section{Meta-Analysis of The Implementation of Blended Learning and Selecting Online Media Used to Learning Outcomes}

Abstract

Technological developments provide many benefits in the world of education, one of them is educational process can be carried out online. Online learning in question is the Blended Learning, with the implementation of the blended learning, it is hoped that it can provide solutions to problem in learning activities especially on learning outcomes. In this study, a meta-analysis of 15 articles from national journals was carried out regarding the application of the Blended Learning model to learning outcomes, the meta-analysis method was used to find the Effect Size value which categorized the success of the Blended Learning. The Blended Learning process is supported by the use of media or platforms that serve as intermediary facilities between teachers and students, the type of platform used in the 15 articles is Google Classroom with an $\overline{E S}$ value $=0.94$, Edmodo with an $\overline{E S}$ value $=0.81$, Whatsapp with a $\overline{E S}$ value $=2.41$, Web-Enhanced Course with $\overline{E S}$ value $=$ 1.34, Quipper School with $\overline{E S}$ value $=0.76$, and LMS with $\overline{E S}$ value $=2.30$. The results of the effect size category fall into moderate to high effects, which means that the meta-analysis of 15 articles from scientific journals shows that the applications of blended learning is proven to be able to improve learning outcomes in students.

Keywords: Blended Learning, Learning Outcomes, Meta analysis

\section{Pendahuluan}

Teknologi pada masa modern telah berkembang sangat pesat, dan telah menunjang berbagai aspek kehidupan termasuk dalam bidang pendidikan. Menurut (Susanti, 2016, p.25), dalam dunia 
pendidikan perkembangan teknologi atau biasa disebut dengan e-learning dapat memudahkan guru untuk berinteraksi dengan peserta didik, serta dapat mempermudah peserta didik untuk memahami isi pelajaran. Maksud dari mudahnya interaksi antara guru dan siswa adalah dengan adanya teknologi e-learning guru dapat terhubung dengan siswa dari tempat yang jauh, sehingga proses pembelajaran dapat tetap berlangsung sebagaimana mestinya dan tidak harus di sekolah. Dengan adanya interaksi yang baik maka proses pembelajaran akan berlangsung secara maksimal, di mana guru akan memberikan penjelasan dan siswa merespon penjelasan yang diberikan oleh guru, dari proses pembelajaran yang baik tersebut maka siswa dapat meningkatkan hasil belajarnya.

Dalam rangka memperoleh peningkatan hasil belajar, maka diperlukan penggunaan media yang sesuai. Media pembelajaran merupakan sebuah komponen alat atau perantara yang utama pada kegiatan pembelajaran. Menurut (Falahudin, 2017, p.402), keutamaan penggunaan media pembelajaran adalah sebagai alat yang membantu seorang guru untuk menyampaikan materi kepada siswa, dan penggunaan media yang sesuai akan memberikan pengaruh terhadap kondisi, motivasi, dan lingkungan belajar. Untuk itu perlu diperhatikan pemilihan media yang paling tepat dan sesuai agar kegiatan pembelajaran dapat berjalan secara maksimal.

Selain media, dalam sebuah proses pembelajaran diperlukan sebuah model pembelajaran. Dengan berkembangnya teknologi, maka dapat pula dikembangkan model pembelajaran yang baru. Salah satu teknologi yang sering dimanfaatkan dalam pembelajaran dewasa ini adalah internet. Keberadaan internet telah memicu munculnya variasi-variasi dalam sebuah proses pembelajaran. Salah satunya adalah blended learning, dalam masa adaptasi kebiasaan baru pandemi covid-19 guru dapat menerapkan pembelajaran blended learning sebagai alternatif pembelajaran yang aman untuk dilaksanakan. Menurut (Adistana, 2016, p.2), blended learning adalah sebuah perpaduan antara kegiatan belajar yang dilakukan di kelas dengan kegiatan belajar yang dilakukan secara online dengan memanfaatkan media online yang ada. Selaras dengan hal tersebut menurut (Rusdiana, Sulhan, Arifin, \& Kamludin, 2020, p.4), blended learning adalah perpaduan pembelajaran di sekolah dan pembelajaran secara jarak jauh yang menggunakan internet sebagai media perantara, dengan banyak pilihan jenis media yang dapat digunakan.

Serta menurut Husamah, 2014 dalam (Tusa'diyah, 2020, p.11), blended learning adalah penggabungan antara pembelajaran langsung secara face to face di sekolah dan pembelajaran yang dilakukan secara virtual dan tidak bertempat di sekolah. Menurut Husamah, 2014 dalam (Tusa'diyah, 2020, p.12) terdapat 3 komponen penting dalam pelaksanaan model pembelajaran Blended Learning, yaitu:

a. Face to face, adalah pembelajaran secara langsung yang bertempat di sekolah yang melibatkan guru dengan siswa.

b. E-Learning, adalah proses pembelajaran yang memanfaatkan internet sebagai perantara dalam pelaksanaan pembelajaran.

c. M-Learning, adalah media yang digunakan dalam melaksanakan pembelajaran online misalnya handphone, tablet, PC, laptop, dan masih banyak lainnya.

Berdasarkan pembagian 3 komponen tersebut dapat dikatakan bahwa dalam pelaksanaan blended learning diperlukan 3 komponen tersebut agar proses pembelajaran blended learning dapat berjalan dengan maksimal. Jika satu di antara tiga komponen tersebut tidak ada, maka belum dapat dikatakan sebagai model pembelajaran blended learning. Untuk itu, bagi para guru sangat penting untuk dapat menguasai keterampilan pembelajaran yang melibatkan ketiga komponen tersebut. 
Dalam masa pandemi covid-19 ini penerapan blended learning menjadi alternatif dalam melangsungkan kegiatan pembelajaran. Karena pada masa ini segala hal dibatasi terutama kegiatan yang dapat menimbulkan kerumunan. Oleh karenanya perlu adanya penyesuaian kepada tenaga pendidik untuk menerapkan blended learning. Penerapan ini memerlukan waktu adaptasi baik kepada guru ataupun kepada siswa, namun dengan adanya berbagai macam teknologi yang berkembang maka hal ini dapat memudahkan proses pembelajaran tersebut. Selain itu guru dan siswa juga harus dibekali dengan pengetahuan tentang bagaimana cara menggunakan portal e-learning yang tersedia agar tercapai kegiatan pembelajaran yang semaksimal mungkin.

Dari uraian yang telah dijelaskan maka diperlukan ringkasan tentang bagaimana keberhasilan blended learning dan penggunaan media online terhadap hasil belajar. Hasil pencarian artikel menunjukkan bahwa telah banyak artikel yang memuat tentang blended learning dan macam-macam penggunaan medianya, maka diperlukan ulasan mengenai hal tersebut dengan cara mengkaji ulang artikel yang ada atau biasa disebut dengan literatur review. Metode pada literatur review ini adalah meta-analisis, menurut (Retnawati, 2018, p.2), meta-analisis digunakan untuk menentukan ditolak atau diterimanya hipotesis dalam suatu penelitian, selain itu meta-analisis dapat menentukan kekuatan hubungan atau perbedaan antara variabel sehingga dapat menghasilkan kesimpulan secara statistik dan representatif. Penentuan tersebut dapat ditetukan dengan cara menghitung nilai effect size pada setiap artikel. Berdasarkan uraian di atas maka tujuan dilakukannya penelitian ini adalah : (1) Menganalisis nilai effect size penerapan model pembelajaran blended learning terhadap hasil belajar ditinjau dari jenjang pendidikan. (2) Menganalisis nilai effect size penerapan model pembelajaran blended learning terhadap hasil belajar ditinjau dari jenis platform yang digunakan. Harapan dari penelitian dengan metode meta-analisis ini adalah agar dapat memberikan manfaat bagi para guru dan seluruh instasi yang terkait.

\section{Metode}

Dari banyaknya metode yang ada maka dipilihlah metode meta-analisis dalam penelitian ini, menurut (Retnawati, 2018, p.2), meta-analisis adalah penelitian yang mengolah dan menganalisa data kuantitatif dari hasil penelitian sebelumnya yang telah dilakukan oleh orang lain, sehingga diperlukan pengumpulan dari beberapa artikel atau jurnal nasional yang memiliki data yang dimaksudkan. Tujuan pengumpulan artikel tersebut untuk menganalisis data yang diperoleh dan setalah dianalisis maka dapat ditarik sebuah kesimpulan. Tujuan meta-analisis menurut (Anwar, 2005, p.3), adalah untuk memperoleh nilai effect size yang dapat menentukan besarnya perbedaan atau kekuatan hubungan antar variabel, dengan cara melakukan analisis terhadap data kuantitatif yang diperoleh dari penelitian sebelumnya. Untuk itu dalam penelitian ini pada setiap artikel dilakukan perhitungan nilai effect size untuk menghitung besar pengaruh penerapan blended learning terhadap hasil belajar. Berikut ini adalah kerangka kerja penelitian metode metaanalisis dari peneliti (Retnawati, 2018, p.9):

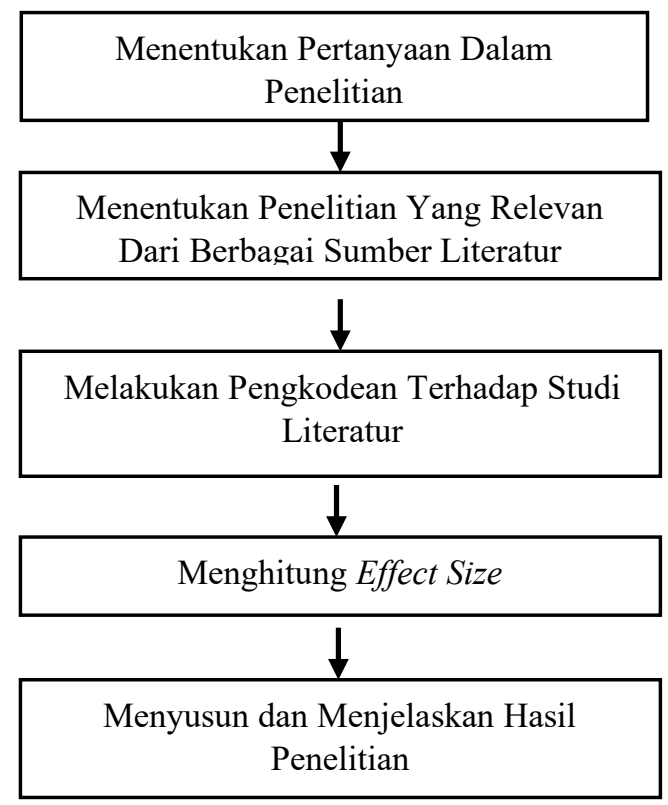


Gambar 1. Kerangka Kerja Penelitian Metode Meta-analisis (Diadaptasi dari Retnawati, 2018, p.9)

Dari kerangka tersebut telah ditentukan pertanyaan dalam penelitian ini yaitu bagaimana pengaruh penggunaan blended learning pada proses pembelajaran dan penggunaan media online terhadap hasil akhir belajar siswa. Setelah itu mulai dilakukan pengumpulan dari beberapa artikel yang sesuai dengan tema yang diambil, setelah artikel terkumpul maka langkah selanjutnya melakukan pengkodean terhadap artikel tersebut. Pengkodean adalah syarat utama dalam meta-analisis dengan tujuan untuk mempermudah dalam pengumpulan serta analisis data, sehingga dibentuklah pengkodean agar dapat menghasilkan informasi yang diperlukan. Pada penelitian ini menggunakan sampel 15 artikel dari jurnal nasional, perolehan 15 artikel dikelompokkan pada tabel 1 yang memuat perbandingan jenjang pendidikan sebagai berikut ini:

Tabel 1. Perbandingan Jenjang pendidikan

\begin{tabular}{ccc}
\hline No & Jenjang Pendidikan & Jumlah \\
\hline 1 & SMA & 5 \\
2 & SMK & 10 \\
\hline & Total & $\mathbf{1 5}$ \\
\hline
\end{tabular}

Berikutnya adalah tabel 2 yang mengelompokkan artikel berdasarkan penggunaan media dalam pelaksanaan pembelajaran model blended learning seperti berikut ini:

Tabel 2. Jenis Media yang Digunakan

\begin{tabular}{ccc}
\hline No & Media Pembelajaran & Jumlah \\
\hline 1 & Google Classroom & 4 \\
2 & Edmodo & 4 \\
3 & LMS & 1 \\
4 & Web Enhanced & 4 \\
& Course & \\
5 & Whatssapp & 1 \\
6 & Quipper School & 1 \\
\hline & Total & $\mathbf{1 5}$ \\
\hline
\end{tabular}

Setelah dilakukan pengkodean maka langkah selanjutnya adalah menghitung nilai effect size pada setiap artikel. Perhitungan effect size dilakukan menggunakan 3 rumus yang berbeda hal ini di karenakan data yang ditemukan pada setiap artikel berbeda-beda metodenya, sehingga dipilihlah 3 rumus ini untuk menyesuaikan dengan data yang ada. Berikut ini rumus perhitungan effect size oleh (Becker \& Park, 2011, p.26):

Rumus 1:

$E S=\frac{\boldsymbol{X} \text { Eksperimen }-\boldsymbol{X} \text { Kontrol }}{S D \text { Kontrol }}$

Rumus 2:

$E S=t \times \sqrt{\frac{1}{n \text { Ekperimen }}+\frac{1}{n \text { Kontrol }}}$

Rumus 3:

$E S=\frac{\overline{(\mathrm{X} p o s t}-\overline{\mathrm{X}} \text { pre)ekperimen }-\overline{\mathrm{X}} \text { post }-\overline{\mathrm{X}} \text { pre }) \text { kontrol }}{\left(\frac{\text { SD pre Kontrol }+ \text { SD pre ERperimen }+ \text { SD post Kontrol }}{\mathrm{s}}\right)}$

Dimana:

$\overline{\mathrm{X}}_{\mathrm{E}} \quad=$ Rerata nilai kelas eksperimen

$\overline{\mathrm{X}}_{\mathrm{K}} \quad=$ Rerata nilai kelas kontrol

SDkontrol= Nilai standart deviasi kelas kontrol

$\mathrm{t}=$ Nilai $\mathrm{t}$ hitung

$\mathrm{n}_{\mathrm{E}} \quad=$ Jumlah sampel pada kelas eksperimen

$\mathrm{n}_{\mathrm{K}} \quad=$ Jumlah sampel kelas kontrol

$\overline{\mathrm{X}}$ post $\quad=$ Rerata nilai posttest

$\overline{\mathrm{X}}$ pre $\quad=$ Rerata nilai pretest

SDpre = Nilai standart deviasi pretest

SDpost = Nilai standart deviasi postest

Perhitungan effect size digunakan untuk mengklasifikasikan nilai tersebut berdasarkan tabel klasifikasi. Tabel klasifikasi ini digunakan untuk menentukan tingkat keberhasilan dari penerapan blended learning dan penggunaan media online terhadap hasil belajar. Berikut ini adalah tabel 3 yang berisi klasisfikasi effect size oleh peneliti Cohen's 1988 dalam (Khoiri, 2019, p.73):

Tabel 3. Klasisfikasi Effect Size Cohen's (1988) dalam (Khoiri, 2019, p.73)

\begin{tabular}{ccc}
\hline No & Effect Size & Kategori \\
\hline 1 & $0 \leq E S \leq 0,2$ & Efek Rendah \\
2 & $0,2 \leq E S \leq 0,8$ & Efek Sedang \\
3 & $E S \geq 0,8$ & Efek Tinggi \\
\hline
\end{tabular}

Hasil Dan Pembahasan

\section{A. Penerapan Blended Learning Terhadap Jenjang pendidikan}

Model blended learning pada era modern ini menjadi model pembelajaran yang banyak dikembangkan dalam berbagai tingkat pendidikan, untuk itu pada 
penelitian ini diambil sampel dari beberapa artikel tentang penerapan blended learning pada jenjang pendidikan SMA dan SMK. Pengambilan sampel ini dilatar belakangi untuk mengetahui bagaimana penerapan model pembelajaran blended learning dan penggunaan media yang sesuai. Selain itu artikel tentang penerapan blended learning lebih banyak ditemukan pada jenjang pendidikan SMA dan SMK, sehingga dipilih jenjang pendidikan tersebut untuk mempermudah penelitian ini. Hasil dari review artikel didapatkan beberapa kelebihan dan kekurangan baik pada jenjang pendidikan SMA maupun jenjang pendidikan SMK. Secara garis besar diambil kesimpulan tentang bagaimana kelebihan dan kekurangan penerapan blended learning pada jenjang pendidikan SMA dan SMK sebagai berikut, menurut (Subagiyo, 2019, p.3), Blended Learning memiliki beberapa kelebihan yaitu:

1. Proses penyampaian materi pembelajaran oleh guru lebih cepat dilakukan dengan teknologi virtual.

2. Peserta didik lebih mudah memahami materi yang disampaikan dengan penggunaan metode serta modifikasi dalam kegiatan pembelajaran.

Selain itu model pembelajaran blended learning memiliki beberapa kekurangan. Menurut Neumeirer 2005 dalam (Halle, 2019, p.13), kekurangan model pembelajaran blended learning yaitu:

1. Keterbatasan peserta didik terhadap penggunaan komputer dan akses internet, sehingga hal tersebut dapat menghambat proses pembelajaran.

2. Peserta didik masih belum menguasai terhadap penggunaan teknologi.

Dalam pelaksanaanya pada jenjang pendidikan SMA ataupun SMK untuk mendapatkan hasil bagaimana penerapan blended learning maka dilakukan perbandingan nilai antara model blended learning dengan model pembelajaran konvensional, sehingga dapat dianalisis bagaimana keefektifan penerapan proses pembelajaran blended learning terhadap hasil belajar. Hasil review menunjukkan dalam pelaksanaan model pembelajaran konvensional kurang menarik minat belajar siswa, karena pada model ini siswa cenderung kurang memperhatikan serta keaktifan siswa dalam mengikuti pembelajaran juga sangat rendah. Menurut (Estika, 2017, p.147), dalam penelitiannya penerapan blended learning pada jenjang pendidikan SMK mempunyai kesimpulan yaitu terdapat adanya perbedaan pada kedua kelas, perbedaan tersebut meliputi perbedaan motivasi belajar yang akhirnya berpengaruh pada hasil belajar peserta didik, hal yang didapatkan adalah pada kelas eksperimen memiliki nilai yang lebih unggul dibandingkan dengan kelas kontrol. Untuk itu perlu dilakukan peningkatan konsentrasi dan keaktifan peserta didik melalui penggunaan blended learning sebagai model pembelajaran, dengan menggunakan berbagai media platform yang tersedia untuk mendukung keberhasilan model pembelajaran blended learning.

\section{B. Penggunaan Media Dalam Blended Learning Terhadap Hasil Belajar Peserta Didik}

Hasil review artikel menunjukkan bahwa penerapan blended learning dilakukan dengan menggunakan berbagai macam media yaitu: Google Classroom, Edmodo, Whatsapp, Web Enhanced Course, Quipper School,dan LMS. Berikut ini adalah penjelasan mengenai beberapa $e$ learning yang digunakan dalam pembelajaran blended learning.

1. Google Classroom

Menurut (Gunawan \& Sunarman, 2017, p.342), Google Classroom dirilis pada 12 Agustus 2014 oleh Google Apps For Education. Google Classroom adalah sebuah platform yang terbentuk seperti kelas maya yang dapat mempermudah seorang guru dalam memberikan materi ataupun tugas secara online. Materi yang diberikan dapat berupa file, gambar, video ataupun link sehingga siswa dapat mengaksesnya dengan mudah. 


\section{Edmodo}

Menurut Inel 2017 dalam (Angraini, Muharini, \& Lestari, 2018, p.2), edmodo adalah sebuah situs pendidikan yang digunakan peserta didik dalam melakukan pembelajaran dengan mengakses konten pembelajaran yang diunggah oleh guru (link,video,file) yang kemudian guru dapat memberikan penugasan dan melakukan penilaian atas hasil belajar peserta didik dan masih banyak lainnya.

3. Whatsapp

Whatsapp menurut (Rahartri, 2019, p.148), adalah aplikasi digital yang dapat mempermudah komunikasi dengan banyak orang selain itu whatsapp juga dapat membagikan berbagai macam konten sesuai dengan fiturnya, dan membutuhkan internet dalam penggunaannya. Dalam penggunaannya sebagai media pembelajaran whatsapp memiliki fitur grup yang dapat digunakan oleh maksimal 256 orang. Dengan ini maka guru bertindak sebagai pemilik grup untuk membagikan materi pembelajaaran dan juga melakukan absensi serta melakukan grup diskusi dengan peserta didik secara online.

4. Web Enhanced Course

Web enhanced course menurut (Achmadi, 2015, p.26), yaitu pemanfaatan internet sebagai pendukung pembelajaran bagi peserta didik untuk meningkatkan pemahaman dan pengetahuan pada peserta didik. Guru dapat membagikan materi serta soal dan melakukan diskusi secara online.

5. Quipper School

Quipper School adalah sebuah portal $e$ learning yang tersedia secara gratis agar dapat melakukan pembelajaran secara online untuk guru dan siswa. Seperti pada umumnya guru bertindak untuk Tabel 4. Tabulasi 7 Artikel Penerapan Blended Learning Terhadap Hasil Belajar Rumus 1

\begin{tabular}{clccccccc}
\hline $\begin{array}{c}\text { Kode } \\
\text { Artikel }\end{array}$ & Penulis, Tahun & Media & $\begin{array}{c}\text { Jenjang } \\
\text { Pendidikan }\end{array}$ & $\overline{\mathbf{X}} \mathbf{E}$ & $\overline{\mathbf{X} K}$ & SDK & $\begin{array}{c}\text { Effect } \\
\text { size }\end{array}$ & Efek \\
\hline AR 01 & Halima Tusa'diyah, & $\begin{array}{c}\text { Google } \\
\text { Classroom } \\
\text { Google }\end{array}$ & SMA & 87,06 & 74,6 & 10,527 & 1,18 & Tinggi \\
AR 02 & Nur Ali, 2019 & SMK & 64 & 55 & 13,270 & 0,678 & Sedang \\
\hline
\end{tabular}


Jurnal Edumaspul, 5 (2), Year 2021 - 316

(Mega Putriana, Gde Agus Yudha Prawira Adistana)

\begin{tabular}{|c|c|c|c|c|c|c|c|c|}
\hline $\begin{array}{c}\text { Kode } \\
\text { Artikel }\end{array}$ & Penulis, Tahun & Media & $\begin{array}{c}\text { Jenjang } \\
\text { Pendidikan }\end{array}$ & $\overline{\mathbf{X}} \mathbf{E}$ & $\overline{\mathbf{X}} \mathbf{K}$ & SDK & $\begin{array}{c}\text { Effect } \\
\text { size }\end{array}$ & Efek \\
\hline AR 03 & $\begin{array}{l}\text { Windy Ayu } \\
\text { Estika,2017 }\end{array}$ & $\begin{array}{c}\text { Google } \\
\text { Classroom }\end{array}$ & SMK & 85,72 & 81,15 & 5,146 & 0,89 & Tinggi \\
\hline AR 04 & $\begin{array}{l}\text { Ni Made Galih } \\
\text { Arya Pramesti,2016 }\end{array}$ & Edmodo & SMK & 88 & 85 & 6,126 & 0,489 & Sedang \\
\hline AR 05 & $\begin{array}{l}\text { Siti Nur Kholifah, } \\
2016\end{array}$ & Edmodo & SMK & 72,84 & 61,89 & 9,938 & 1,101 & Tinggi \\
\hline AR 06 & $\begin{array}{l}\text { A.Farihah } \\
\text { M,Sugiarti, } \\
\text { Melati Masri,2016 }\end{array}$ & $\begin{array}{c}\text { Web } \\
\text { enhanced } \\
\text { course }\end{array}$ & SMA & 85,3 & 71,14 & 11,58 & 1,221 & Tinggi \\
\hline AR 07 & $\begin{array}{l}\text { Ricarda Fatima } \\
\text { Natalia Halle, } 2019\end{array}$ & Whatsapp & SMA & 81,46 & 54,52 & 11,170 & 2,411 & Tinggi \\
\hline
\end{tabular}

Di bawah ini adalah tabel 5 yang masing penelitian dengan menggunakan berisikan hasil review dari 6 artikel untuk rumus yang kedua, dengan tabel menentukan nilai effect size pada masing- sebagai berikut ini:

Tabel 5. Tabulasi 6 Artikel Penerapan Blended Learning Terhadap Hasil Belajar dengan Rumus 2

\begin{tabular}{|c|c|c|c|c|c|c|c|c|}
\hline $\begin{array}{l}\text { Kode } \\
\text { Artikel }\end{array}$ & Penulis, Tahun & Media & $\begin{array}{c}\text { Jenjang } \\
\text { Pendidikan }\end{array}$ & $\mathbf{n E}$ & nK & t hitung & $\begin{array}{l}\text { Effect } \\
\text { Size }\end{array}$ & Efek \\
\hline AR 08 & $\begin{array}{lr}\text { Wiratama } & \text { Darmawan, } \\
\text { Dedi } & \text { Kuswandi, } \\
\text { Henry } & \text { Praherdhiono, } \\
2020 & \end{array}$ & $\begin{array}{c}\text { Google } \\
\text { Classroom }\end{array}$ & SMK & 20 & 20 & 3,193 & 1,009 & Tingi \\
\hline AR 09 & $\begin{array}{l}\text { Nur Aeni, Titi } \\
\text { Prihatin, Yuli Utanto, } \\
2017\end{array}$ & Edmodo & SMK & 36 & 36 & 2,161 & 0,509 & Sedang \\
\hline AR 10 & Sidiq Subagiyo, 2019 & Edmodo & SMA & 33 & 34 & 4,672 & 1,141 & Tinggi \\
\hline AR 11 & $\begin{array}{l}\text { Rita Kurniawati, } \\
\text { Hardjono, Wardi, } \\
2014\end{array}$ & $\begin{array}{c}\text { Web } \\
\text { enhanced } \\
\text { course }\end{array}$ & SMK & 38 & 38 & 4,541 & 1,041 & Tingi \\
\hline AR 12 & Susanti, 2016 & $\begin{array}{c}\text { Web } \\
\text { enhanced } \\
\text { course }\end{array}$ & SMK & 15 & 15 & 2,65 & 0,967 & Tinggi \\
\hline AR 13 & $\begin{array}{l}\text { Sulihin B. Sjukur, } \\
2012\end{array}$ & $L M S$ & SMK & 31 & 31 & 9,046 & 2,297 & Tinggi \\
\hline
\end{tabular}

Berikut ini adalah tabel 6 yang berisikan hasil review dari 2 artikel untuk menentukan nilai effect size pada masing-

masing penelitian dengan menggunakan rumus yang ketiga, sebagai berikut ini:

Tabel 6. Tabulasi 2 Artikel Penerapan Blended Learning Terhadap Hasil Belajar dengan Rumus 3

\begin{tabular}{|c|c|c|c|c|c|c|c|c|c|c|c|c|}
\hline $\begin{array}{c}\text { Kode } \\
\text { Artikel }\end{array}$ & $\begin{array}{c}\text { Penulis, } \\
\text { Tahun }\end{array}$ & Media & $\begin{array}{c}\text { Jenjang } \\
\text { Pendidikan }\end{array}$ & $\begin{array}{c}\overline{\text { Xpost }} \\
\text { E }\end{array}$ & $\begin{array}{c}\overline{\text { Xpre }} \\
\text { E }\end{array}$ & $\begin{array}{c}\overline{\mathbf{X} p o s t} \\
\text { K }\end{array}$ & $\begin{array}{c}\overline{\mathbf{X}} \text { pre } \\
\text { K }\end{array}$ & $\begin{array}{c}\text { SDpre } \\
\text { K }\end{array}$ & $\begin{array}{c}\text { SDpre } \\
\text { E }\end{array}$ & $\begin{array}{c}\text { SDpost } \\
\text { K }\end{array}$ & $\begin{array}{c}\text { Effect } \\
\text { Size }\end{array}$ & Efek \\
\hline AR 15 & $\begin{array}{l}\text { Yuni Pratiwi, } \\
\text { Parijo, Warneri, } \\
2010\end{array}$ & $\begin{array}{c}\text { Quipper } \\
\text { School }\end{array}$ & SMA & 71,8 & 52,67 & 63,7 & 55,2 & 14,8 & 10,91 & 16,04 & 0,763 & Sedang \\
\hline
\end{tabular}

Dari hasil tabel tabulasi dapat diperoleh nilai effect size pada masingmasing kaitan yang akan dijelaskan seperti di bawah ini:
1. Besar Pengaruh Penerapan Model Blended Learning pada Jenjang Pendidikan SMA dan SMK 
Jurnal Edumaspul, 5 (2), Year 2021 - 317

(Mega Putriana, Gde Agus Yudha Prawira Adistana)

Perhitungan effect size penerapan blended learning pada jenjang pendidikan SMA dan SMK digambarkan pada gambar 2 dengan membandingkan nilai effect size yang telah diketahui, seperti di bawah ini:

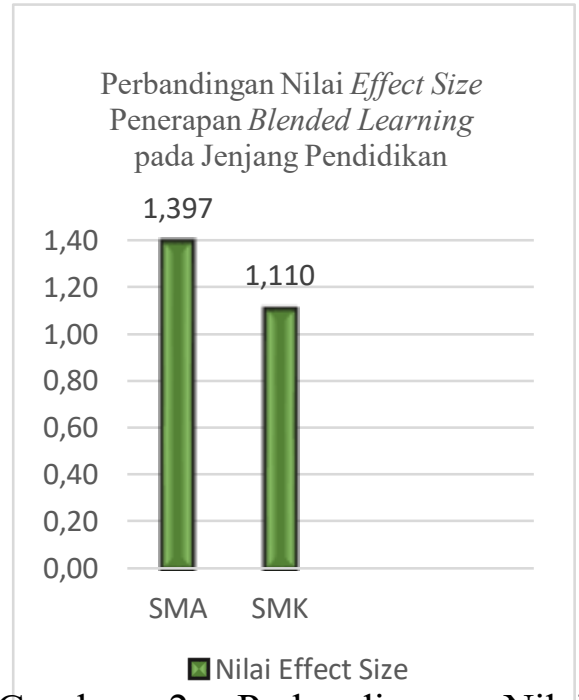

Gambar 2. Perbandingan Nilai Effect Size Penerapan Blended Learning pada Jenjang Pendidikan

Hasil meta-analisis penerapan blended learning menunjukan pengaruh yang sangat tinggi pada jenjang pendidikan SMA maupun SMK. Dilihat dari perhitungan rata-rata nilai Effect Size dari 5 artikel pada jenjang pendidikan SMA yaitu senilai 1,397 dengan kategori efek yang tinggi dan rata-rata nilai effect Size dari 10 artikel pada jenjang pendidikan SMK yaitu 1,110 dengan kategori efek yang tinggi. Hasil dari nilai effect size tersebut menunjukkan penerapan blended learning memiliki efek yang tinggi, hal ini menunjukkan bahwa penerapan blended learning efektif jika diterapkan pada proses pembelajaran pada jenjang pendidikan SMA maupun SMK. Menurut (Susanti, 2016, p.25), Blended Learning dikatakan efektif karena terbukti berhasil meningkatkan hasil belajar pada peserta didik, selain itu juga dapat diketahui dari adanya ketertarikan siswa dalam mengikuti model pembelajaran yang memanfaatkan internet sehingga timbul motivasi belajar yang lebih besar yang kemudian berpengaruh kepada pemahaman tentang materi pembelajaran dan juga hasil belajar.

2. Pengaruh Penggunaan Media Pembelajaran pada Penerapan Blended Learning

Penggunaan media pembelajaran juga berpengaruh terhadap hasil belajar pada penerapan blended learning yang digambarkan pada gambar 3 , seperti di bawah ini:

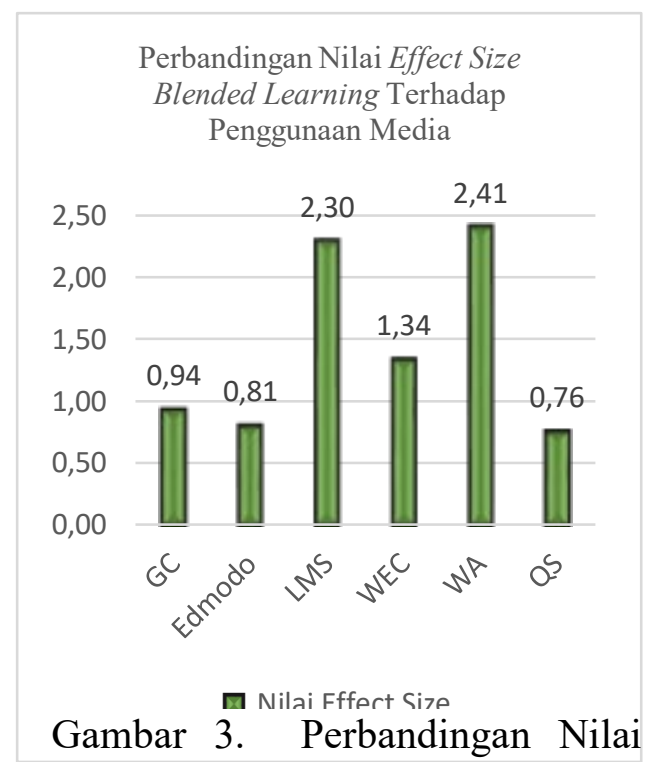

Effect Size Blended Learning terhadap Penggunaan Media

GC : Google Classroom

LMS : Learning Management System

WEC: Web Enhanced Course

WA : Whatsapp

QS : Quipper Sschool

Dari hasil merata-rata nilai effect size terhadap penggunaan media didapatkan hasil untuk penggunaan media google classroom dari 4 artikel didapatkan nilai rata-rata effec size sebesar 0,94 termasuk kedalam kategori efek tinggi. Untuk penggunaan edmodo dari 4 artikel didapatkan nilai rata-rata effec size sebesar 0,81 termasuk kedalam kategori efek tinggi. Penggunaan Learning Management System dari 1 artikel didapatkan nilai effec size sebesar 2,30 termasuk kedalam kategori pengaruh yang tinggi. Penggunaan $\mathrm{Web}$ Enhanced Course dari 4 artikel didapatkan nilai rata-rata effec size 
sebesar 1,34 termasuk kedalam kategori pengaruh yang tinggi. Penggunaan Whatsapp dari 1 artikel didapatkan nilai effec size sebesar 2,41 termasuk kedalam kategori pengaruh yang tinggi. Penggunaan Quipper School dari 1 artikel didapatkan nilai effect size 0,76 masuk dalam kategori efek sedang. Dari analisis yang dilakukan secara keseluruhan baik pada SMA maupun SMK bahwa urutan media yang memiliki pengaruh terhadap hasil belajar siswa adalah Whatsapp, Learning Management System, Web Enhanced Course, Google Classroom, Edmodo, dan terakhir adalah Quipper School. Menurut (Halle, 2019, p.14), penggunaan whatsapp memiliki pengaruh yang tinggi hal ini dikarenakan banyaknya fitur yang terdapat pada whatsapp yang meliputi gambar, teks, video, dan suara serta mudahnya peggunaan whatsapp sebagai sarana komunikasi antara guru dengan siswa untuk melakukan diskusi. Kemudahan penggunaan whatsapp tersebut memudahkan siswa untuk mengikuti kegiatan pembelajaran secara jarak jauh. Dari beberapa penggunaan media dalam penerapan model pembelajaran blended learning yang meliputi whatsapp, learning management system, web enhanced course, google classroom, edmodo, dan quipper school dapat disimpulkan bahwa setiap penggunaan media berpengaruh kepada hasil belajar yang artinya hasil belajar siswa mengalami kemajuan.

\section{Simpulan}

Hasil dari meta-analisis yang telah dilakukan terhadap 15 artikel penerapan blended learning dan pemilihan media online yang digunakan terhadap hasil belajar didapatkan hasil bahwa:

1. Pada jenjang pendidikan SMA dan SMK penerapan model pembelajaran blended learning terbukti efektif untuk diterapkan hal tersebut dapat diketahui dari nilai $\overline{E S}$ pada jenjang pendidikan SMA dengan nilai 1,397 dengan kategori tinggi dan nilai $\overline{E S}$ pada jenjang SMK yaitu 1,110 dengan kategori tinggi. Dengan nilai yang diperoleh dapat disimpulkan yaitu dengan diterapkannya blended learning memberikan dampak positif dalam hal peningkatkan hasil belajar siswa di jenjang pendidikan SMA maupun SMK.

2. Dalam penggunaan media pada jenjang pendidikan SMA dan SMK didapatkan urutan media yang berpengaruh terhadap hasil belajar adalah Whatsapp dengan nilai $\overline{E S}$ 2,41, Learning Management System dengan nilai $\overline{E S}$ 2,30, Web Enhanced Course dengan nilai $\overline{E S} 1,34$, Google Classroom dengan nilai $\overline{E S}$ 0,94, Edmodo dengan nilai $\overline{E S}$ 0,81, dan Quipper School dengan nilai $\overline{E S} 0,76$. Whatsapp memiliki pengaruh yang sangat tinggi dikarenakan mudahnya penggunaan whatsapp dan juga banyaknya fitur yang tersedia didalamnya berupa gambar, file, audio dan juga video yang dapat dikirimkan oleh guru kepada siswa, selain itu dengan menggunakan whatsapp guru dapat dengan mudah berkomunikasi dan berdiskusi dengan siswa selama kegiatan pembelajaran berlangsung. Dari komunikasi dan pemahaman yang baik siswa dapat mengembangkan ilmu yang didapat serta mampu meningkatkan hasil belajarnya. Dengan demikian dapat disimpulkan yaitu dengan diterapkannya blended learning menggunakan platform whatsapp, learning managemnt system, web enhanced course, google classroom, edmodo dan quipper school sangat berpengaruh untuk meningkatkan hasil belajar pada siswa.

\section{Saran}

Saran yang disampaikan dalam penelitian ini adalah: (1) Kepada dosen terkait agar penelitian meta-analisis ini dapat dikembangkan agar menjadi penelitian yang lebih kompleks dalam mengolah data-data yang ada, sehingga dapat digunakan sebagai penelitian dalam menyelesaikan tugas akhir 
Jurnal Edumaspul, 5 (2), Year 2021 - 319

(Mega Putriana, Gde Agus Yudha Prawira Adistana)

atau skripsi. (2) Kepada guru SMA maupun SMK dapat menjadikan blended learning sebagai alternatif model pembelajaran jarak jauh dengan memperhatikan pemilihan platform yang sesuai. (3) Kepada mahasiswa yang ingin meneliti artikel sejenis ini diharapkan dapat mengumpulkan data sebanyak dan semaksimal mungkin sehingga hasil yang didapatkan lebih akurat. (4) Kekurangan dalam penelitian ini adalah sampel yang diteliti terhadap blended learning hanya terbatas pada jenjang pendidikan SMA dan SMK, disarankan ada penelitian lebih lanjut untuk meneliti penerapan blended learning pada jenjang pendidikan dari perguruan tinggi hingga sekolah dasar, sehingga di masa yang akan datang blended learning dapat menjadi model pembelajaran yang efisien untuk digunakan.

\section{Daftar Pustaka}

[1] Adistana, Gde Agus Yudha Prawira. (2016). Pengaruh blended learning station-rotation (kooperatif vs kompetitif) dan gaya kognitif, terhadap keterampilan intelektual manajemen konstruksi. 1-6.

[2] Angraini, M. R., Muharini, R., \& Lestari, I. (2018). Penerapan Blended Learning Berbasis Edmodo Terhadap Minat dan Hasil Belajar Siswa SMAN 9 Pontianak, 1-12.

[3] Anwar, Rusnawa. (2005). Meta Analisis. Bandung: UNPAD.

[4] Becker, K., \& Park, K. (2011). Effects Of Integrative Approaches Among Science, Technology, Engineering, And Mathematics (Stem) Subjects On Students' Learning. Journal Of Stem Education, 12(5), 23-38.

[5] Estika, W. (2017). Pengembangan Blended Learning Dengan Strategi Flipped Classroom Pada Mata Pelajaran Desain Multimedia Di Smk Pgri Ploso, 2(2), 141-148.

[6] Falahudin, I. (2017). Pengaruh Brain Training Terhadap Tingkat Inteligensia
Pada Kelompok Usia Dewasa Muda. Diponegoro Medical Journal (Jurnal Kedokteran Diponegoro), 6(2), 402416.

[7] Gunawan, F. I., \& Sunarman, S. G. (2017). Pengembangan Kelas Virtual Dengan Google Classroom Dalam Keterampilan Pemecahan Masalah (Problem Solving) Topik Vektor Pada Siswa SMK Untuk Mendukung Pembelajaran. Prosiding Seminar Nasional Etnomatnesia, 340-348.

[8] Halle, R. F. N. (2019). Penerapan Model Blended Learning Berbasis Whatsapp Untuk Meningkatkan Kemandirian Belajar, Berpikir Kritis Dan Hasil Belajar Siswa Kelas X MIPA SMAK Kesuam Mataram Tahun Pelajaran 2018/2019 Pada Materi Usaha Dan Energi, 1-147.

[9] Quiper.com. About Quipper. diakses pada Tanggal 08 April 2021. Https://www.quipper.com/id/about.

[10] Khoiri, A. (2019). Meta Analysis Study: Effect Of Stem ( Science Technology Engineering And Mathematic ) Towards Achievement, 9(1), 71-82.

[11] Muhammad, T. (2017). Perancangan Learning Management System Menggunakan Konsep Computer Supported Collaborative Learning Abstraksi This Time Many Universities Have Implemented E-Learning To Support Learning Activities. However Amik Hass Bandung The Campus Where Researchers C. Jurnal Produktif, 1, 35-63.

[12] Rahartri. (2019). “Whatsapp" Media Komunikasi Efektif Masa Kini (Studi Kasus Pada Layanan Jasa Informasi Ilmiah Di Kawasan Puspiptek). Visi Pustaka, 21(2), 147-156.

[13] Retnawati, H. Dkk. (2018). Pengantar Analisis Meta. Yogyakarta: Parama Publishing.

[14] Rusdiana, A., Sulhan, M., Arifin, I. Z., 
Jurnal Edumaspul, 5 (2), Year 2021 - 320

(Mega Putriana, Gde Agus Yudha Prawira Adistana)

\& Kamludin, U. A. (2020). Application

Of The Poe2we Model Based On

Google Classroom Blended Learning

In Learning During The Wfh Covid-19

Pandemic. Scientific Writing Of The

Bandung State Islamic University 2020, 1-10.

[15] Subagiyo, S. (2019). Penerapan Model Blended Learning Untuk Meningkatkan Pemahaman Konsep Termokimia Siswa, 1(1), 1-8.

[16] Susanti. (2016). Efektifitas Pembelajaran Blended Learning Model Web Enhanced Course Terhadap Hasil Belajar Siswa Kelas XI SMK Gunung Sari 1 Makassar, 5, 23-32.

[17] Tusa'diyah, H. (2020). Penerapan Blended Learning Menggunakan Aplikasi Google Classroom Terhadap Hasil Belajar Siswa Pada Materi Gelombang Mekanik Kelas XI MIPA SMAN 2 Payakumbuh, 2507(1), 1-9.

\section{Profil penulis:}

Mega putriana, Lahir di Bojonegoro, 21 Oktober 1999 . Penulis saat ini sedang menempuh pendidikan di Universitas Negeri Surabaya, Fakultas Teknik, Jurusan Teknik Sipil, Prodi S1 Pendidikan Teknik Bangunan dari tahun $2017-2021$. 